\title{
Hidden costs of antiretroviral treatment: the public health efficiency of drug packaging
}

This article was published in the following Dove Press journal:

Drug Design, Development and Therapy

5 August 2015

Number of times this article has been viewed

\author{
Àngels Andreu-Crespo',* \\ Josep M Llibre ${ }^{2,3, *}$ \\ Glòria Cardona-Peitx' \\ Ferran Sala-Piñol' \\ Bonaventura Clotet ${ }^{2,4}$ \\ Xavier Bonafont-Pujol' \\ 'Pharmacy Department, ${ }^{2} \mathrm{HIV}$ \\ Unit and "Lluita contra la SIDA" \\ Foundation, University Hospital \\ Germans Trias i Pujol, Badalona, \\ ${ }^{3}$ Universitat Autònoma de Barcelona, \\ ${ }^{4}$ Universitat de Vic-Universitat Central \\ de Catalunya (UVIC-UCC), Vic, \\ Barcelona, Spain \\ *These authors contributed equally \\ to the work
}

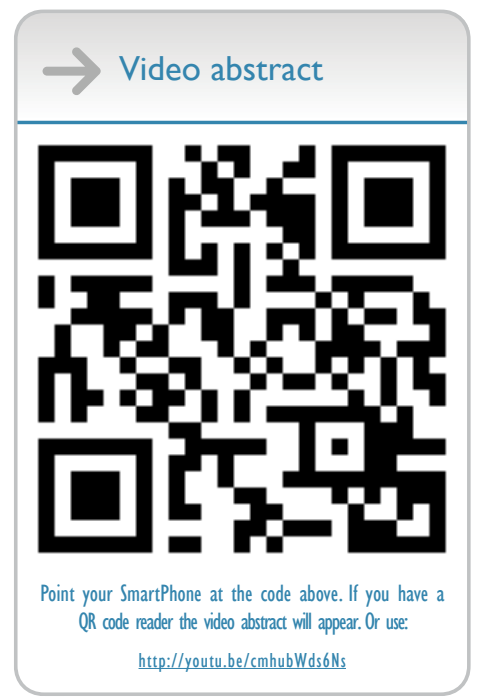

Correspondence: Josep M Llibre HIV Unit, Hospital Universitari Germans Trias i Pujol, Ctra de Canyet, s/n08916 Badalona (Barcelona), Spain Email jmllibre@flsida.org

\begin{abstract}
While the overall percentage of unused antiretroviral medicines returned to the hospital pharmacy is low, their cost is quite high. Adverse events, treatment failure, pharmacokinetic interactions, pregnancy, or treatment simplification are common reasons for unplanned treatment changes. Socially inefficient antiretroviral packages prevent the reuse of drugs returned to the hospital pharmacy. We defined antiretroviral package categories based on the excellence of drug packaging and analyzed the number of pills and costs of drugs returned during a period of 1 year in a hospital-based HIV unit attending to 2,413 treated individuals. A total of 6,090 pills (34\% of all returned antiretrovirals) - with a cost of $47,139.91 €$ - would be totally lost, mainly due to being packed up in the lowest efficiency packages. Newer treatments are packaged in low-excellence categories of packages, thus favoring the maintenance of these hidden costs in the near future. Therefore, costs of this low-efficiency drug packaging, where medication packages are started but not completed, in high-cost medications are substantial and should be properly addressed. Any improvement in the packaging by the manufacturer, and favoring the choice of drugs supplied through efficient packages (when efficacy, toxicity, and convenience are similar), should minimize the treatment expenditures paid by national health budgets.
\end{abstract}

Keywords: antiretroviral treatment, cost efficacy, drug packaging, treatment change

\section{Introduction}

Disbursement in antiretroviral treatment (ART) drugs within the context of a public health shortage of resources has increased the interest in pharmacoeconomical analyses of the available regimens for both treatment-naïve and -experienced individuals. ${ }^{1,2}$

In Western Europe, the classic concepts of efficacy, effectiveness, and efficiency - supported by the European Medicines Agency's actions at the time of commercialization - must be completed with equity of care, the efficiency of drug packages, and their potential impact on public health budgets. ${ }^{3}$

In Spain, there is universal access to ART, and drugs are delivered by law only through hospital-based pharmacies. Not infrequently, patients return opened packages to the pharmacy due to unexpected toxicity, treatment changes, pharmacokinetic interactions, pregnancy, or incomplete adherence. ${ }^{4}$ The efficiency of these packages, which vary significantly in their quality standards, has an influence on their potential for reuse, and the impact on the cost of treatment for the health system may eventually be considerable. ${ }^{5}$

Socially efficient packaging in ambulatory care hospital-dispensed drugs should be the one that is best adapted to unit-dose dispensation. In addition, it should facilitate patient compliance, allowing for an easy and hygienic review of the ingested and remaining doses with no need to manipulate either the packaging or the pharmaceutical forms, particularly those that are unused. Moreover, in directly observed ART, drugs that are properly packed permit better control, allowing the delivery of just the 
needed doses in every dispensation (ie, adjusted to weekly methadone delivery in drug users).

We established antiretroviral package categories based on the excellence of drug packaging and analyzed the number of pills and the cost of drugs returned during a period of 1 year in a hospital-based HIV unit.

\section{Methods}

We defined a classification system for the so-called social efficiency of antiretroviral drug packages that could also be applicable to any other family of high-cost drugs used for outpatients or inpatients (ie, hepatitis $\mathrm{C}$ direct antivirals). The classes were as follows:

Class A: Drug packed in unit doses with complete information (name of the drug, dosage in $\mathrm{mg}$, lot number, and expiry date) in each unit, thus maintaining complete information if returned when the external package is opened. No unit doses are opened in the returned packages (Figure 1).

Class B: Drug packed in blisters with complete information only in the blister, but not in every unit dose, without special conservation conditions. Should be initially repackaged in unit doses in the pharmacy before dispensation to ensure class A excellence, with complete tracking information in every unit.

Class C: Drug packed in plastic containers with complete information written only on a label over the container, with no special conservation conditions. It would allow to supply a repackaged drug to the patient.

Class D: Drug packed in plastic containers with any manufacturer's warning that the product cannot be placed outside of the original package due to special conditions of conservation (fridge, humidity) that will not allow either initial unit dose repackaging or reusing an opened container.

Class $\mathrm{B}$ and class $\mathrm{C}$ packing increase pharmacy department budgets in terms of human resources, time, and repacking materials. In class D packing, all of the contents will be lost once the container is opened, regardless of being returned.

In order to deliver only the necessary amount of pills until the next visit, or to deliver a predefined schedule of medication via each pharmacy department, class A packages would exhibit optimal social efficiency, whereas class D would demonstrate the worst. Depending on the social efficiency of the drug that patients withdraw, the returned "old" one would immediately become a wasted drug.

The change of a class B or class $\mathrm{C}$ drug into a class A drug requires internal pharmacy technician work. The current cost of this change is approximately $0.034 €$ per pill, according to conditioning material suppliers and human resources obtained through our hospital price list. An experienced technician repackages approximately 214 pills per hour (1,500 pills/day).

\section{Results}

The hospital-based pharmacy in our HIV unit served 2,413 treated individuals during the year of study. Patients generated 23,574 visits to the pharmacy during this period, and they experienced a total of 1,051 treatment changes for any reason. Most of the treatment changes were not foreseeable.

The pharmacy department delivered 48,325 antiretroviral drug packages $(2,529,137$ pills). A total amount of $122,945 €$ was returned in opened antiretroviral packages. Of these packages, 6,090 pills (34\% of all returned antiretrovirals) - with a cost of $47,139.91 €$ - would be totally lost, mainly due to being packed up in class $\mathrm{C}$ and class $\mathrm{D}$ boxes. This would be the equivalent to treating 78 individuals with a standard coformulation of rilpivirine/tenofovir/emtricitabine during 1 month.

We have classified all the current ART specialties depending on their social efficiency as supplied in Spain, the UK, and the USA (Table 1). US packaging shows a


Figure I Class A and D packaging.

Notes: (A) Class A (optimal social efficiency) packaging of a drug featuring unit doses with complete information (name of the drug, dosage in mg, lot number, and expiry date) in each unit. (B) Class D (lowest social efficiency) packaging in plastic containers with the manufacturer's warning that the product cannot be placed outside of the original package due to special conditions of conservation (humidity). 
greater deal of class $\mathrm{C}$ and class $\mathrm{D}$ bottles when compared to Europe.

Class A and class B packages returned in bad condition represented only $1.1 \%$ of the cost and $75,805 €$ came from returned packages in good condition that could potentially be reused.

\section{Discussion}

During a period of 1 year, the percentage of antiretroviral drugs returned to the hospital pharmacy was low. However, the cost of these drugs is high, and therefore there is a significant economic budget loss through unused antiretroviral medicines returned to the hospital pharmacy that cannot be reused due to being supplied in low-excellence packages (approximately one-third of all returned packages).
For hospital inpatients, the excellence in use of ART requires class A packed drugs that allow for administration in unit doses, thus minimizing time hours consumed by nurses in drug administration, reducing medication errors, and improving drug stocks in hospital wards.

The European Commission has singled out specific countries to make particular recommendations to increase the cost effectiveness of the health care sector, and in the case of Spain, there is particular interest in further rationalizing pharmaceutical spending, including ambulatory drugs dispensed in hospitals. ${ }^{6}$ Further to this point, the European Association of Hospital Pharmacists has encouraged European authorities to identify the drug with all the items we define as class A efficiency, and also to include a barcode to allow unit dose administration in hospitals. Barcode technology substantially reduces the rate

Table I Efficiency class of all antiretroviral drugs available in Spain, the USA, and the UK

\begin{tabular}{|c|c|c|c|c|}
\hline \multirow[t]{2}{*}{$\overline{\text { Drug }}$} & \multicolumn{3}{|c|}{ Efficiency class of the packaging } & \multirow{2}{*}{$\begin{array}{l}\text { License } \\
\text { year, Spain }\end{array}$} \\
\hline & Spain & US & UK & \\
\hline Retrovir $^{\circledast} 100 \mathrm{mg}, 250 \mathrm{mg}$, or $300 \mathrm{mg}$ & A & C & A & 1987 \\
\hline Reyataz $^{\circledast} 200$ mg & A & C & C & 2004 \\
\hline Sustiva ${ }^{\circledR} 600 \mathrm{mg}$ & $A$ & C & $A$ & 2002 \\
\hline Viramune ${ }^{\circledR} 200 \mathrm{mg}$ or $400 \mathrm{XR} \mathrm{mg}$ & $A$ & $A$ & A & 2011 \\
\hline Zidovudine ${ }^{\circledR} 100 \mathrm{mg}, 250 \mathrm{mg}$, or $300 \mathrm{mg} * *$ & $A$ & $\mathrm{~N} / \mathrm{A}$ & $\mathrm{N} / \mathrm{A}$ & 1996 \\
\hline Teva-Efavirenz ${ }^{\circledR} 600$ mg** & $A$ & $\mathrm{~N} / \mathrm{A}$ & $\mathrm{N} / \mathrm{A}$ & 2013 \\
\hline Nevirapine Teva ${ }^{\circledR} 200 \mathrm{mg}^{* *}$ & $A$ & $\mathrm{~N} / \mathrm{A}$ & $N / A$ & 2012 \\
\hline Celsentri ${ }^{\circledR} 150 \mathrm{mg}$ or $300 \mathrm{mg}$ & B & $C$ & B & 2007 \\
\hline Kaletra ${ }^{\circledR}$ tablets & B & $\mathrm{D}$ & B & 2010 \\
\hline Kivexa ${ }^{\circledR} 600-300 /$ Epzicom $^{\circledR}$ I pill once-a-day & B & C & B & 2004 \\
\hline Trizivir $^{\circledR}$ capsules & B & C & B & 2001 \\
\hline Videx ${ }^{\circledR} 200 \mathrm{mg}, 250 \mathrm{mg}$, or $400 \mathrm{mg}$ & B & $D^{*}$ & B & 2000 \\
\hline Zerit $^{\circledR} 20 \mathrm{mg}, 30 \mathrm{mg}$, or $40 \mathrm{mg}$ & B & $D^{*}$ & B & 1996 \\
\hline Ziagen $^{\circledR} 300$ mg & B & B & B & 1999 \\
\hline Lamivudine generic $300 \mathrm{mg}\left(\mathrm{Normon}^{\circledR}\right)^{* *}$ & B & $\mathrm{N} / \mathrm{A}$ & $\mathrm{N} / \mathrm{A}$ & 2012 \\
\hline Combivir $^{\circledR}$ one pill twice daily & B & $\mathrm{B}, \mathrm{C}$ & B & 1998 \\
\hline Emtriva $^{\circledR} 200$ mg & C & $C$ & $\mathrm{D}$ & 2003 \\
\hline Epivir $^{\circledR}$ I 50 mg or 300 mg & C & C & $\mathrm{C}$ & 2002 \\
\hline Invirase ${ }^{\circledR} 500 \mathrm{mg}$ & C & $D^{*}$ & $\mathrm{~N} / \mathrm{A}$ & 2005 \\
\hline Isentress ${ }^{\circledR}$ & C & $C$ & $\mathrm{C}$ & 2007 \\
\hline Prezista $^{\circledR} 600 \mathrm{mg}$ or $800 \mathrm{mg}$ & C & C & $\mathrm{C}$ & 2009 \\
\hline Reyataz $^{\circledR} 200 \mathrm{mg}$ or $300 \mathrm{mg}$ & C & C & $\mathrm{C}$ & 2008 \\
\hline Sustiva ${ }^{\circledR} 200 \mathrm{mg}$ & C & C & $\mathrm{C}$ & 1999 \\
\hline Telzir $^{\circledast} 700$ mg/Lexiva ${ }^{\circledR}$ one pill twice daily & C & D* & C & 2004 \\
\hline Tivicay ${ }^{\circledR}$ & C & C & C & 2014 \\
\hline Viread $^{\circledR} 245 \mathrm{mg}$ & $\mathrm{C}$ & $D^{*}$ & $\mathrm{C}$ & 2002 \\
\hline Aptivus ${ }^{\circledR} 250 \mathrm{mg}$ & $\mathrm{D}$ & $\mathrm{D}$ & $\mathrm{D}$ & 2005 \\
\hline Atripla ${ }^{\circledR}$ & $\mathrm{D}$ & $\mathrm{D}$ & $\mathrm{D}$ & 2007 \\
\hline Crixivan ${ }^{\circledR} 200 \mathrm{mg}$ or $400 \mathrm{mg}$ & $\mathrm{D}$ & $\mathrm{D}$ & $\mathrm{D}$ & 1996 \\
\hline Edurant $^{\circledR}$ & $\mathrm{D}$ & $\mathrm{D}$ & $\mathrm{D}$ & 2012 \\
\hline Eviplera/Complera $^{\circledR}$ & $\mathrm{D}$ & $\mathrm{D}$ & $\mathrm{D}$ & 2012 \\
\hline Intelence ${ }^{\circledR} 100 \mathrm{mg}$ and $200 \mathrm{mg}$ & $\mathrm{D}$ & $\mathrm{D}$ & $\mathrm{D}$ & 2008,2011 \\
\hline Norvir $^{\circledR} 100 \mathrm{mg}$ tablets & $\mathrm{D}$ & $\mathrm{D}$ & $\mathrm{D}$ & 2010 \\
\hline Stribild ${ }^{\circledR}$ & $\mathrm{D}$ & $\mathrm{D}$ & $\mathrm{D}$ & 2013 \\
\hline Truvada $^{\circledR} 200-245 \mathrm{mg}$ one pill once-a-day & $\mathrm{D}$ & $\mathrm{D}$ & $\mathrm{D}$ & 2005 \\
\hline Triumeq $^{\circledR}$ one pill once daily & $\mathrm{D}$ & $\mathrm{D}$ & $\mathrm{D}$ & 2015 \\
\hline
\end{tabular}

Notes: * "Keep container tightly closed" is specified by the manufacturer in the container. **Generic drugs analyzed only in Spain brands. Abbreviation: N/A, not applicable. 
of errors in order transcription and medication administration, and it reduces potential adverse drug events and interactions. ${ }^{7}$

Establishing strategies to reduce the waste of unused medicines is an unmet need. ${ }^{4,5,8}$ Unopened unit dose (class A) drugs that are returned inside the hospitals can be reused. However, in ambulatory care, this reusing is usually not allowed due to the impossibility of granting the quality of drugs once delivered to outpatients.

Unfortunately, newer antiretrovirals - mainly, the new three drug combos, Eviplera/Complera, Stribild, and Triumeq,--are commonly packaged in class $\mathrm{C}$ and class $\mathrm{D}$ categories, thus promoting the maintenance of these hidden costs in the near future. Any improvement in the excellence of packaging by the manufacturer, and favoring the choice of drugs supplied through more efficient packages (whenever efficacy, toxicity, and convenience are similar), should minimize treatment expenditures paid by national health budgets.

\section{Conclusion}

In summary, while the overall percentage of unused antiretroviral medicines returned to the hospital pharmacy is low, their cost is quite high. Therefore, the hidden costs of this low-efficiency drug packaging in wasted drugs in these kinds of medications are substantial and should be properly addressed.

Drug regulatory authorities should consider including the concept of social efficiency of the packaging in the authorization process of high-cost specialty medicines delivered through hospital dispensing to ambulatory patients, as many of these drugs are actually manufactured in Europe.

\section{Acknowledgments}

This work was supported by the "Gala contra la SIDA Barcelona 2013" and the Red de Investigación en SIDA, RD12/0017/0002 as part of the Plan Nacional R + D + I and cofinanced by ISCIII-Subdirección General de Evaluación y el Fondo Europeo de Desarrollo Regional (FEDER).

We are indebted to Anna Casanellas for her collaboration in the cost analyses. This work was presented in part at: HIV Drug Therapy Glasgow Congress 2014; November 2-6, 2014; Glasgow, UK. Abstract P077.

\section{Author contributions}

AAC and JML wrote the first draft of this manuscript. All authors contributed toward data analysis, drafting and revising the paper and agree to be accountable for all aspects of the work.

\section{Disclosure}

Josep M Llibre has served as an advisor and speaker, and has been awarded with grants for clinical research from Gilead Sciences, Merck Sharp \& Dohme, ViiV Healthcare, BristolMyers Squibb, and Janssen-Cilag. Bonaventura Clotet has served as an advisor and speaker, and has been awarded with grants for research from Gilead Sciences, Merck Sharp \& Dohme, ViiV Healthcare, Abbot, Bristol-Myers Squibb, and Janssen-Cilag. Àngels Andreu-Crespo has served as an advisor or speaker for Gilead Sciences, Janssen-Cilag, Abbott Laboratories, Merck Sharp \& Dohme, and ViiV Healthcare. The other authors report no conflicts of interest in this work.

\section{References}

1. Blasco AJ, Llibre JM, Berenguer J, et al; GESIDA ART Cost-efficacy Study Group. Costs and cost-efficacy analysis of the 2014 GESIDA/ Spanish National AIDS Plan recommended guidelines for initial antiretroviral therapy in HIV-infected adults. Enferm Infecc Microbiol Clin. 2015;33(3):156-165.

2. Department of Health and Human Services Panel on Antiretroviral Guidelines for Adults and Adolescents. Guidelines for the Use of Antiretroviral Agents in HIV-1-Infected Adults and Adolescents. Washington, DC: Department of Health and Human Services; 2015. Available from: http://aidsinfo.nih.gov/ContentFiles/AdultandAdolescentGL.pdf. Accessed July 17, 2015.

3. European Medicines Agency (EMA) [webpage on the Internet]. Human medicines: regulatory information. Available at: http:// www.ema.europa.eu/ema/index.jsp?curl=pages/regulation/landing/ human_medicines_regulatory.jsp\&mid=. Accessed July 17, 2015.

4. Coma A, Modamio P, Lastra CF, Bouvy ML, Mariño EL. Returned medicines in community pharmacies of Barcelona, Spain. Pharm World Sci. 2008;30(3):272-277.

5. Mackridge AJ, Marriott JF. Returned medicines: waste or a wasted opportunity? J Public Health (Oxf). 2007;29(3):258-262.

6. European Association of Hospital Pharmacists [webpage on the Internet]. EAHP EU Monitor - 04 June 2014. Brussels, Belgium: European Association of Hospital Pharmacists; 2014. Available from: http://www. eahp.eu/news/EU-monitor/eahp-eu-monitor-04-june-2014. Accessed July 17, 2015.

7. Poon EG, Keohane CA, Yoon CS, et al. Effect of bar-code technology on the safety of medication administration. $N$ Engl J Med. 2010;362(18): $1698-1707$.

8. Bergen PJ, Hussainy SY, George J, Kong DCM, Kirkpatrick CMJ. Safe disposal of prescribed medicines. Australian Prescriber. 2015;38:90-92.
Drug Design, Development and Therapy

\section{Publish your work in this journal}

Drug Design, Development and Therapy is an international, peerreviewed open-access journal that spans the spectrum of drug design and development through to clinical applications. Clinical outcomes, patient safety, and programs for the development and effective, safe, and sustained use of medicines are a feature of the journal, which

\section{Dovepress}

has also been accepted for indexing on PubMed Central. The manuscript management system is completely online and includes a very quick and fair peer-review system, which is all easy to use. Visit http://www.dovepress.com/testimonials.php to read real quotes from published authors.

Submit your manuscript here: http://www.dovepress.com/drug-design-development-and-therapy-journal 